\title{
The Consequences of the COVID-19 Lockdown on Stalking Victimisation
}

\author{
Kelly Bracewell $^{1}$ (I) $\cdot$ Paul Hargreaves $^{1} \cdot$ Nicky Stanley $^{1}$ \\ Accepted: 3 September 2020 / Published online: 10 September 2020 \\ (C) Springer Science+Business Media, LLC, part of Springer Nature 2020
}

\begin{abstract}
Stalking involves repeated unwanted communication, harassment, and intrusive behaviour. This brief report draws on a service evaluation undertaken immediately prior to and during the 2020 COVID-19 crisis. The pandemic creates a paradox when considering safety in the home, but it is important to recognise the dangers this presents to many victims of stalking. The information presented in this report is based on existing literature and early evidence from semi-structured interviews and discussions with 15 victims and six practitioners. Whilst lockdown measures might appear to be a time when victims are less accessible to their stalkers, early evidence from this study suggests that their vulnerability is increased. Technology has helped to facilitate stalking behaviours by providing stalkers with new approaches to control, humiliate, threaten and isolate their victims. Some lockdown restrictions have provided increased opportunities for stalkers to monitor their victims and the professional uncertainty and recognition around stalking has continued, coupled with delays in the criminal justice system. The COVID-19 crisis has reversed gains made by stalking victims and has imprisoned some victims in their homes making their whereabouts easier to monitor. Stalking behaviour has not ceased as a result of the COVID-19 restrictions and the risk of harm to victims remains significant. Effective practice, policy and legal responses are required for both the victims and perpetrators of stalking during the pandemic and afterwards.
\end{abstract}

Keywords Stalking $\cdot$ Stalkers $\cdot$ COVID-19 $\cdot$ Interpersonal violence

\section{Introduction}

Stalkers and stalking behaviour permeate every aspect of a victim's life including their mental and emotional health, employment and social opportunities. For these victims, the restrictions on daily life imposed in response to COVID-19 (coronavirus) have had particular consequences which have so far remained relatively overlooked. This brief report highlights the implications of the COVID-19 crisis for stalking including its impact on victims, perpetrator behaviour, criminal justice responses and specialist service responses. The information presented is based on early evidence from semistructured interviews and discussions with 15 victims and six practitioners gathered in the course of an ongoing service evaluation of Paladin, a UK stalking advocacy service. The

Kelly Bracewell

KBracewell1@uclan.ac.uk

1 School of Social Work, Care and Community, University of Central Lancashire, Office 131 Eden Building, Preston PR1 2HE, UK evaluation began in early March 2020, immediately prior to the UK lockdown in response to COVID-19. The pandemic has challenged individuals, the economy, services and the domestic violence and abuse (DVA) sector in ways that are increasingly recognized (Williamson et al. 2020; Social Care Institute for Excellence 2020). Whilst the impact of the global public health emergency was not a planned element of our investigation, the effects became evident. Paladin statistics (March to June 2020) indicated an increase of over 50\% in agency referrals compared to the same period in 2019 and a $40 \%$ increase compared to the 3 months prior to lockdown.

\section{Background}

Definitions of stalking vary across the literature due to variations in its nature, severity and the law. Most definitions refer to an intentional pattern of intrusive and intimidating behaviour which creates fear or anxiety in the victim (Logan and Walker 2017). Stalking has been defined by Paladin as 'a pattern of unwanted, fixated and obsessive behaviour which 
is intrusive and causes fear of violence or serious alarm or distress'. Whilst there is an absence of a definitive legal definition in England and Wales, legislation sets out acts or omissions which provide examples of stalking. UK legislation against stalking was introduced in 1997 with the Protection from Harassment Act. Two new offences of stalking were inserted into this Act in 2012: harassment, which involves a course of conduct that amounts to stalking (s.2A(1) PHA 1997) and Stalking - s.4A (1) PHA 1997 which involves the fear of violence or serious alarm and distress. Although stalking is often associated with DVA, it has its own patterns of behaviour (Quinn-Evans et al. 2019). Yet, despite legal recognition, research has shown that professional, public and even victim perceptions of stalking are often inaccurate (Boehnlein et al. 2020) and thus the response remains inadequate. The pandemic has been associated with an escalation in reports of interpersonal violence (IPV) (Bradbury-Jones and Isham 2020), resulting in heightened public awareness of DVA and its impact and the development of guidance and resources (Landis, 2020; UNDP 2020). However, the specific effects of COVID-19 on stalking have received less recognition.

There were an estimated 1,472,000 victims of stalking in England and Wales in 2018/19 (ONS 2019). Yet there is a large discrepancy between the numbers reporting having experienced stalking and crimes actually recorded (HMICFRS and HMCPSI 2017). There has also been an increase in recorded stalking offences (ONS 2019) but a decrease in charges being brought against the perpetrator (BBC News 2018). Further, prosecuting perpetrators does not necessarily lead to cessation of stalking behaviour (Eke et al. 2011). Stalking is a prevalent problem and can escalate to severe assaults or homicide (HMIC and HMCPSI 2017; MoncktonSmith et al. 2017). Often attempts by victims to distance themselves from their stalker aggravates the stalking behaviour and increases the risk of serious harm (Quinn-Evans et al. 2019). In non-fatal cases, stalking is often a highly traumatising experience that has long lasting psychological and physical effects such as depression, posttraumatic stress, panic disorders, and anxiety (Dreßing et al. 2005). Stalking related fear impacts on the everyday lives of victims, with severely heightened worries about their personal safety, vulnerability and risk (Logan and Walker 2019). Victim fears are not unfounded as half of those stalkers who make threats then act on them (MacKenzie et al. 2009). Monckton-Smith et al.'s (2017) UK study of 358 homicides, all of which involved a female victim and a male perpetrator, revealed stalking behaviour as an antecedent in $94 \%$ of cases.

Stalkers employ a variety of behaviours, including but not exclusively: sending unwanted messages, presents or letters; making unwanted calls; following and surveillance; using offensive or sexual language in communications; threats; sexual harassment and physical assault (Dreßing et al. 2005). In the age of digital technology, digital communication and social networking provide a convenient way for perpetrators to maintain and escalate their stalking behaviours. Constant text messages and phone calls create a pattern of control which is psychologically harmful (Fraser et al. 2010; Short et al. 2015). These behaviours convey the stalker's omnipotence and omnipresence, leaving the victim feeling that they cannot escape (Stark 2012; Woodlock 2017).

Most victims of stalking are female, and most offenders are male (Kuehner et al. 2012). Women are also more likely than men to experience fear due to stalking (Sheridan and Lyndon 2010). Lifetime estimates show that approximately one in five women and one in ten men experience stalking (since the age of 16) (ONS, 2019). Most victims know their stalker: the largest group of stalkers ( $46 \%$ of all cases) are former intimate partners (Metropolitan Police 2020). People stalked by an expartner are at greater risk of serious harm (McEwan et al. 2007) and stalking is often more prolonged (Eke et al. 2011). The widely held that stalking is mostly inflicted by strangers conflicts with the experiences of most victims (Weller et al. 2013). Recent research highlights this discrepancy between the public view of stalking and actual stalking behaviour, the challenges to charging and prosecution, and the burden placed on victims (Boehnlein et al. 2020). The fear of not being believed and the fear of the consequences of reporting are common reasons for non-reporting. When victims do report, most experience inaction or inappropriate action from the police (Quinn-Evans, et al. 2019; Taylor-Dunn et al. 2018). Practitioners working across different criminal justice and victim service agencies report that stalking victims need to be believed, have their feelings validated and not have their experiences minimised or trivialised (Boehnlein et al. 2020).

\section{COVID-19 and Awareness of Stalking}

The measures announced over recent months to tackle COVID-19 have drastically changed many aspects of daily life. The UK government acknowledged that the initial order to stay at home caused anxiety for those who were experiencing or at risk of DVA (Home Office 2020). Updated guidance (Home Office 2020) included exemption from social isolation for victims who needed to leave their homes. The UK government made heavy use of social media to raise awareness of sources of help for DVA victims and announced $£ 2$ million in additional funding for the national DVA helpline and online support. The media revealed a surge in DVA globally (Bradbury-Jones and Isham 2020) and increased reports of women being murdered by known men in their homes have been publicised (Ingala Smith 2020). Safety planning advice guides for DVA during the pandemic have been released by specialist DVA charities. However, there has been less 
awareness around the impact of lockdown on stalking behaviour, despite stalkers being ex-partners in many cases. This brief report aims to increase awareness of stalking in this context.

\section{Methods}

Face-to-face interviews were undertaken with all five Independent Stalking Advocacy Caseworkers (ISACs) employed by Paladin. This information was supplemented by telephone and email discussions with the service manager and staff. All staff were female. Paladin made initial contact with service users to offer them the opportunity to participate in telephone interviews to explore their experiences of the service. All 15 service users approached agreed to participate (14 females, 1 male). They were provided with a voucher to acknowledge their time and contribution to the evaluation.

The 15 service users were aged between 21 and 52 years and came from locations across England. Eleven were of White British ethnicity; four were of Black, Asian and Minority Ethnic (BAME) heritage. The average length of stalking experienced was 18.4 months, the longest being 4 years and the shortest just under 6 months. Victims were most likely to be stalked by an ex-partner $(n=8)$ but also included acquaintances $(n=3)$, friends $(n=2)$, clients $(n=1)$ and strangers $(n=1)$. Victims described other people in their lives, such as friends or family members, also being harassed by their stalker (see Bocij 2004). All interviews were audio recorded with participant consent, transcribed verbatim and analysed thematically using NVivo v12. Close reading of transcripts identified the recurring theme of the impact of COVID19. Below we discuss these findings in relation to existing literature.

\section{Results}

\section{The Implications of the COVID-19 Crisis for Stalking Behaviour}

Paladin experienced a 50-70\% increase in initial requests for support via email from both victims and wider services in the 3 months from April 2020 compared to the previous 3 months. There are multiple interlinked motivations for stalking. Mullen et al. (1999) distinguished five main types of stalkers drawn from a clinical sample: rejected, intimacy-seeking, incompetent, resentful, and predatory. These stalking typologies do not represent an exhaustive list; however, they do provide a useful reference to briefly consider the implications of the COVID-19 pandemic for stalkers and their behaviours.

Stalkers who wished to pursue or rekindle a relationship featured in many service user accounts. Indeed, the 'rejected stalker' has been reported to be the most common type of stalker (Mullen et al. 1999; HMIC and HMCPSI 2017). Rejected stalkers' sense of loss manifests as frustration, anger and vindictiveness, fuelled by jealousy and sadness which they direct toward their victim (Mullen et al. 1999). Isolation as a result of social restrictions in response to the pandemic can heighten the stalkers' sense of loss. This category of stalkers may see the increased vulnerability of victims and limited childcare options, as an opportunity for reconciliation or revenge.

In the case of 'intimacy seeking stalkers', reduced opportunity for physical surveillance of their victim during lockdown measures can escalate other methods of stalking behaviour. Paladin staff observed increasing resentment of some stalkers due to the initial changes caused by lockdown where their usual stalking methods or the victim's routine was affected. One ex-partner could not continue surveillance of his victim and in the first week of lockdown employed a private detective who was found outside her house by the police in the early hours of the morning. Another stalker placed a tracker on his victim's car while in another case, the stalker used members of the local community to continue surveillance, including parents of children attending the same school as the victim's children. Restrictions on victims' movements during lockdown also provided opportunities for resentful and predatory stalkers to escalate their behaviour. Staff described a stalker who increased his contact via post alongside sending malicious reports to child protection services and charities.

Confinement to the home provides stalkers with increased opportunities for surveillance, since victims can be readily located. Whilst stalkers should also be largely confined to their home, their behaviour demonstrates they are not lawabiding, compliant citizens and therefore are unlikely to adhere to lockdown measures. To date, restrictions have not been heavily enforced in the UK which makes adherence less likely and undermines the supposition that stalking victims would be safer under lockdown.

\section{Digital Safety}

The COVID-19 pandemic has implications for the form and frequency of stalking behaviours. Stalking may continue over a number of years with perpetrators deeply invested in their behaviour. Loss of employment, working from home or being furloughed increases perpetrators' time and capacity to modify and/or escalate their stalking behaviour. Paladin staff were concerned that those stalkers who may not have used technology in the past are now more adept in utilising digital methods to access information about their victims. In the context of lockdown, victims reported increases in cyber abuse and online stalking. For example, one victim who had previously experienced online stalking every few weeks; described the frequency increasing to a daily occurrence. Staff described an 
increase in 'revenge porn' being used and sent to family and friends before live streaming. Other stalkers created multiple Facebook profiles using the victim's photograph to impersonate her or used others to convey threats. The increased use of new apps such as 'House Party' and 'Zoom' provide additional ways for stalkers to contact their victims.

Prior to lockdown, police advised victims to restrict their use of social media posts to increase online safety. Whilst closing a social media account might seem like a minor inconvenience, it provides the perpetrator with another approach in a pattern of coercive control that aims to isolate and intimidate a victim. This creates a barrier for victims who are fearful of such technology due to stalkers using online platforms to garner information about them. Huge increases in the use of social media platforms to maintain social networks and lessen feelings of isolation under lockdown have been reported (Singh 2020). For many stalking victims, restricted use of technology intensifies their feelings of isolation.

Social distancing measures together with the closure of face-to-face services have increased reliance on online methods for shopping, banking, medical appointments, remote working and accessing support. Yet studies show that such technology is commonly used by stalkers to monitor, control, or harass their target (Short et al. 2015). In the current situation where digital technology has become the only method of communication or means of working for many, stalking victims are at increased risk of exposure to their stalker online. Some cases of online stalking have started since the lockdown. The closure of public places, such as libraries/colleges/charities, that previously provided opportunities for safe use of the internet, and a move to remote working was exacerbating victim isolation and increasing risk. Even when victims used technology to enhance their safety, it could work against them. In one case, the victim remained in the marital home which had CCTV installed. Her ex-partner continued to access this after their separation and constantly texted and emailed her about her movements on an almost daily basis. A number of victims believed their online communication (mobile phone, laptop etc) had been hacked and they were unable to communicate safely. Another victim suspected her house had been 'bugged', although she visited friends prior to lockdown, she was unable to do this now. There are also concerns around the safety of any COVID-19 track and trace app that may be introduced: it is not known if the safety of victims can be addressed by such an app and staff expressed fears that stalkers may use this to locate their victims by falsely stating they have been in contact.

\section{Physical Safety}

Physical safety is a priority for stalking victims. Many victims are forced to make significant changes to their lives, with consequences for their home life, leisure activities, employment and social networks, including family relationships. Some experience severe disruptions as a direct consequence of their victimisation, such as losing or changing employment and relocating. However, once victims are restricted to their homes, they become easier to locate: Paladin's manager described victims as 'sitting ducks' under lockdown. Initial UK lockdown guidance recommended daily exercise. This allowed stalkers to pass a victim's residence on multiple occasions. From 11th May exercise was extended from once a day to 'as often as you wish' (Cabinet Office 2020) and travelling by car for exercise 'irrespective of distance' was permitted. Stalkers have taken advantage of this guidance to monitor their victims, travelling to their homes or workplace. Following the closure of many public places, venturing out of the home may present a greater risk for stalking victims, with fewer people available to offer potential sources of help if victims are threatened. One woman who previously went grocery shopping with her mother or friend whilst her children were at school was required to take her children shopping alone under COVID-19 restrictions. Her perpetrator had previously made threats to kill both her and her children and the absence of a companion significantly increased her feelings of fear. Practical advice from Paladin staff on how to stay safe and better protect themselves outside the home provided much needed reassurance. Staff described adapting this safety advice to consider the impact of COVID-19 and working flexible hours to meet the needs of victims. As well as physical safety, being stalked has implications for a victim's emotional health and wellbeing.

\section{Emotional Safety and Mental Health}

The various forms of social isolation created by stalking were a prominent feature across all interviews. Isolation was exacerbated by lockdown measures, particularly if victims were reluctant to use or trust digital technology. Social isolation was a prominent feature in service users' accounts, and some described coming out of isolation prior to the COVID-19 crisis, after long periods of confinement following Paladin support. Returning to work and socialising again was described as giving them a sense of control. However, the potential loss of employment, being furloughed or working from home alongside the imposed social restrictions may signal a return to isolation. Speaking to the national media, one victim described how she was already living in lockdown conditions prior to the COVID-19 outbreak, but since restrictions were imposed, her home had become a prison, as she was no longer able to invite family and friends (Oppenheim 2020). Isolation is often heightened in cases where the stalker is an ex-partner. In a relationship where the perpetrator exerted high levels of control, the victim's support network has often been stripped away (Stark 2012). 
Evidence documenting the detrimental impact of the COVID-19 pandemic on mental health in the general population is accumulating (Courts and Tribunals Judiciary 2020; Wang et al. 2020; Pancani et al. 2020). Infection fears, increased financial pressures, caring responsibilities and uncertainty about the future characterises anxiety in the general population and compounds existing anxieties and fears felt by stalking victims. Victim surveys undertaken prior to the pandemic demonstrate the negative impact of stalking on mental health and wellbeing (Kuehner et al. 2012; Woodlock 2017) with the fear instilled by stalking behaviour a significant predictor of PTSD symptoms (Fleming et al. 2012). The unpredictability of the COVID-19 outbreak will inevitably heighten existing mental health difficulties. Added concerns for personal safety, financial stresses and restricted access to support brought about by the pandemic and resulting measures, intensify the fears and senses of loss of control reported by stalking victims. Improving a victim's psychological wellbeing is an important aspect of Paladin support which encourages service users to access local support and social groups to alleviate some of the impact of their stalking experiences. This was seen as helpful by service users. However, recent service closures and social distancing measures limit the options available to victims in this regard.

\section{Childcare Issues}

The loss of access to childcare is a prominent issue for many parents in the current crisis, with schools, nurseries and childminders closed, work now located in the home and no options for sharing childcare with friends or family. Childcare issues may heighten the risks for victims of stalking by an expartner, particularly where the perpetrator is the child's parent. When informal support networks are reduced in response to stalking, schools and nurseries may have provided victims' only opportunity for accessing childcare. Their closure provides opportunities for a stalker to try and rekindle a relationship by offering childcare or enact revenge. For example, during the early stages of lockdown, one ex-partner emailed the victim's solicitor stating that she was a bad mother for taking her children out of the house and putting the children at risk. This confirmed that he was monitoring her whereabouts.

The closure of child contact centres during the pandemic has the potential to increase risks for stalking victims. The parents of children subject to a Child Arrangements Order are advised to communicate with each other and temporarily vary the arrangements set out in the order to one they consider to be safe (Courts and Tribunals Judiciary 2020). In the absence of regulated contact provision, perpetrators can pressure victims to adhere to unsafe court arrangement orders or to make alternative arrangements (Scotland and Lindfield 2020). In one case, a child refused overnight contact with her father and his girlfriend as they did not adhere to the restrictions. The stalker blamed the victim and applied for full custody.

\section{Criminal Justice Response}

The police response prior to COVID-19 was frequently described negatively by staff and victims. Consistent with previous research (e.g. Taylor-Dunn et al. 2018; HMCPSI 2017), service users described a lack of understanding by police who failed to take them seriously. This continued under COVID19 with long delays in applying for protection orders and downloading evidence from electronic devices. However, staff also reported that, since the UK lockdown, they had received an improved response from some police forces. They attributed this to reductions in other forms of crime, which have given police the opportunity to focus on issues such as stalking. Nevertheless, concerns about transmission of COVID-19 can impede the criminal justice response. In one example, a perpetrator was not arrested due to claims that he was self-isolating with COVID-19 symptoms.

Staff and service users criticised the handling of stalking cases by the Crown Prosecution Service (CPS), with low rates of prosecution, inadequate court capacity to list cases and the adjournment of court dates or trials. Since COVID-19 restrictions were introduced, the Courts and Tribunal Judiciary have drawn up contingency plans for court hearings to be consolidated into fewer buildings. However, the closure of many judicial buildings means the inevitable postponement of cases (Courts and Tribunals Judiciary 2020). Staff identified delays for plea hearings and trials for lower stalking offences, breaches of restraining orders and non-molestation orders, meaning victims were left in limbo without a timescale for resolution whilst the perpetrator's behaviour remained uncontrolled. Once restrictions are lifted, there will be a sizeable backlog for the courts to deal with, resulting in long delays. One trial set for the end of March 2020 was adjourned until June and then again until August 2020, prolonging the victim's ordeal.

\section{Next Steps}

All staff and service users participating in the evaluation discussed the importance of raising awareness of stalking, its impact, the law and the specialist provision available. This was considered important for agencies, employers, the general public and victims themselves who may not recognise stalking behaviours due to a general lack of knowledge in comparison to other forms of IPV. Service users consistently flagged up their experience of feeling validated by Paladin staff; their experiences were finally being recognised and acknowledged. This feeling of validation was not often available in their interactions with other agencies or sometimes with friends and family due to commonly held misconceptions about stalking. 
Public and professional recognition of the heightened risks of stalking, and the continued risks of perpetrator behaviour under COVID-19 would improve the protection of victims and reduce feelings of isolation. Improved recognition and response could be achieved through increased media reporting and funding of specialist provision and awareness activities; DVA service provision provides a model for such a shift.

In the context of COVID-19, we have observed political, media and academic debate on the issue of DVA, but there has been less focus on stalking. This represents a gap in awareness which reflects a failure to forge a link between experience of DVA and stalking. This is surprising given that many victims are stalked by former intimate partners. Paladin data showed that stalking and harassment were characterised by the coercive control and high levels of fear which perpetrators elicited by ensuring the victim knew they were under surveillance. These are now acknowledged as key features of DVA (Stark 2012). There is a need for wider understanding of the nature and extent of stalking and its relationship with DVA. The COVID-19 crisis has demonstrated that increased awareness would be valuable.

\section{Conclusions}

Messages broadcast in response to the COVID-19 crisis have urged us to stay safe at home but this may not be an option for many stalking victims. While lockdown might appear to be a time when victims are less accessible to their stalkers, the early evidence from this study suggests that their vulnerability has increased. It has been argued that 'one of the more terrifying tactics used by stalkers is to make the victim feel that she has no privacy, security, or safety, and that the stalker knows and sees everything' (Fraser et al. 2010: 44). The COVID-19 crisis has made victims more accessible to perpetrators whose surveillance tactics appear to have intensified. In this context, isolation and fear may be exacerbated for victims. While increasing opportunities for perpetrators to stalk their victims, digital technology can enable offer positive opportunities for contact with support networks. The unique risks for stalking victims in this context require a bespoke response which is currently lacking.

The lack of awareness surrounding stalking and appropriate responses is linked to a lack of resources around IPV generally and stalking specifically. Policy makers need to be alerted to the extent and severity of risks for stalking victims if resources are to be directed to specialist intervention and prevention services, both during the COVID-19 crisis and afterwards. Research on previous pandemics does not appear to have considered the impact on stalking, although recent work highlights risk factors for increased violence against women and children more broadly (Peterman et al. 2020). First et al.'s (2017) work around violence after a disaster provides some helpful suggestions to consider the extent of potential issues in the longer-term, such as community education and awareness programmes. Further research is needed to establish whether the early indications from this study are representative of victims' experiences more broadly. It would be helpful to investigate the impact of different aspects of intersectionality such as poverty, race, ethnicity, age, ability or religion. Such research could help inform the service response during a pandemic as well as strengthening the response to stalking victims in the longer term.

\section{References}

BBC News. (2018). Stalking reports treble as prosecution rates fall (2018, July 20), BBC News. Retrieved from https://www.bbc.co.uk/news/ uk-england-44887574

Bocij, P. (2004). Cyberstalking: Harassment in the internet age and how to protect your family. Westport: Greenwood Publishing Group.

Boehnlein, T., Kretschmar, J., Regoeczi, W., \& Smialek, J. (2020). Responding to stalking victims: Perceptions, barriers, and directions for future research. Journal of Family Violence, 1-14. https://doi. org/10.1007/s10896-020-00147-3.pdf.

Bradbury-Jones, C., \& Isham, L. (2020). The pandemic paradox: The consequences of COVID-19 on domestic violence. Journal of Clinical nursing., 29, 2047-2049. https://doi.org/10.1111/jocn. 15296.

Cabinet Office (2020) Guidance. Coronavirus outbreak FAQs: what you can and can't do Updated 11 May 2020 Available from: https:// www.gov.uk/government/publications/coronavirus-outbreak-faqswhat-you-can-and-cant-do/coronavirus-outbreak-faqs-what-youcan-and-cant-do

Courts and Tribunals Judiciary. (2020) Coronavirus (COVID-19) Advice and Guidance. Retrieved at: https://www.judiciary.uk/coronavirusCOVID-19-advice-and-guidance/COVID-19 and Mental Wellbeing. (2020, April 16).

Dreßing, H., Kuehner, C., \& Gass, P. (2005). Lifetime prevalence and impact of stalking in a European population: Epidemiological data from a middle-sized German city. The British Journal of Psychiatry, 187(2), 168-172. https://doi.org/10.1192/bjp.187.2.168.

Eke, A. W., Hilton, N. Z., Meloy, J. R., Mohandie, K., \& Williams, J. (2011). Predictors of recidivism by stalkers: A nine-year follow-up of police contacts. Behavioral Sciences \& the Law, 29(2), 271-283. https://doi.org/10.1002/bs1.975.

First, J. M., First, N. L., \& Houston, J. B. (2017). Intimate partner violence and disasters: A framework for empowering women experiencing violence in disaster settings. Affilia, 32(3), 390-403. https://doi.org/10.1177/0886109917706338.

Fleming, K. N., Newton, T. L., Fernandez-Botran, R., Miller, J. J., \& Burns, V. E. (2012). Intimate partner stalking victimization and posttraumatic stress symptoms in post-abuse women. Violence Against Women, 18(12), 1368-1389.

Fraser, C., Olsen, E., Lee, K., Southworth, C., \& Tucker, S. (2010). The new age of stalking: Technological implications for stalking. Juvenile and Family Court Journal, 61(4), 39-55. https://doi.org/ 10.1111/j.1755-6988.2010.01051.x.

HMIC AND HMCPSI. (2017). Living in fear-the police and CPS response to harassment and stalking: A joint inspection by HMIC and HMCPSI. HMIC 2017. Available from: https://www. justiceinspectorates.gov.uk/hmicfrs/publications/living-in-fear-thepolice-and-cps-response-to-harassment-and-stalking/ 
Home Office. (2020). Coronavirus (COVID-19): Support for victims of domestic abuse. Guidance. London: Home Office Available from: https://www.gov.uk/government/publications/coronavirus-COVID19-and-domestic-abuse/coronavirus-COVID-19-support-forvictims-of-domestic-abuse.

Ingala Smith, K. (2020) 2020: UK women killed by men or where a man is the principal suspect. Retrieved from: https://kareningalasmith. com/2020/04/14/2020/

Kuehner, C., Gass, P., \& Dreßing, H. (2012). Mediating effects of stalking victimization on gender differences in mental health. Journal of Interpersonal Violence, 27(2), 199-221. https://doi.org/ 10.1177/0886260511416473.

Landis, D. (2020). Policy brief: Gender-based violence (GBV) and COVID-19: The complexities of responding to "the shadow pandemic". CARE: USA https://www.care-international.org/.

Logan, T. K., \& Walker, R. (2017). Stalking: A multidimensional framework for assessment and safety planning. Trauma, Violence, \& Abuse, 18(2), 200-222. https://doi.org/10.1177/ 1524838015603210 .

Logan, T. K., \& Walker, R. (2019). The impact of stalking-related fear and gender on personal safety outcomes. Journal of Interpersonal Violence. https://doi.org/10.1177/0886260519829280.

MacKenzie, R., McEwan, T. E., Pathe, M., James, D. V., Ogloff, J. R., \& Mullen, P. E. (2009). Stalking risk profile: Guidelines for the assessment and management of stalkers. Australia: Monash University.

McEwan, T., Mullen, P. E., \& Purcell, R. (2007). Identifying risk factors in stalking: A review of current research. International Journal of Law and Psychiatry, 30(1), 1-9. https://doi.org/10.1016/j.ijlp.2006. 03.005 .

Metropolitan Police. (2020). What you can do about harassment. Retrieved from: https://www.met.police.uk/cp/crime-prevention/ harassment/af/Harassment/harassment/

Monckton-Smith, J., Szymanska, K., \& Haile, S. (2017). Exploring the relationship between stalking and homicide. Suzy Lamplugh Trust.

Mullen, P., Pathe, M., Purcell, R., \& Stuart, G. (1999). A study of stalkers. American Journal of Psychiatry, 156, 1244-1249. https:// doi.org/10.1176/ajp.156.8.1244.

Office for National Statistics. (2019). Stalking: Findings from the crime survey for England and Wales. London. Retrieved from: https:// www.ons.gov.uk/peoplepopulationandcommunity/crimeandjustice/ datasets/stalkingfindingsfromthecrimesurveyforenglandandwales

Oppenheim, M. (2020). 'I am scared to go into the garden': Stalking victims reveal horror of lockdown as reports rise, The Independent. (April 25) Retrieved at https://www.independent.co. uk/news/uk/home-news/coronavirus-stalking-domestic-abuseharassment-paladin-a9483341.html

Pancani, L., Marinucci, M., Aureli, N., \& Riva, P. (2020). Forced social isolation and mental health: A study on 1006 Italians under COVID19 quarantine. (preprint) https://doi.org/10.31234/osf.io/uacfj.

Peterman, A., Potts, A., O’Donnell, M., Thompson, K., Shah, N., OerteltPrigione, S., \& van Gelder, N. (2020). Pandemics and violence against women and children. Center for Global Development Working Paper, 528.

Quinn-Evans, L., Keatley, D. A., Arntfield, M., \& Sheridan, L. (2019). A behavior sequence analysis of victims' accounts of stalking behaviours. Journal of Interpersonal Violence. https://doi.org/10.1177/ 0886260519831389.

Scotland, M., \& Lindfield, G. (2020). Parenting plans \& child arrangements orders. London: Law Business Research (May 26) Retrieved at https://www.lexology.com/library/detail.aspx?g=4b8dc9fd-838c4cbc-8780-0e4cee013fb1.

Sheridan, L., \& Lyndon, A. (2010). The influence of prior relationship, gender, and fear on the consequences of stalking victimization. Sex Roles, 66, 340-350. https://doi.org/10.1007/s11199-010-9889-9.

Short, E., Guppy, A., Hart, J. A., \& Barnes, J. (2015). The impact of cyberstalking. Studies in Media and Communication, 3(2), 23-37. https://doi.org/10.11114/smc.v3i2.970.

Singh, D. (2020) Lockdown effect: No rules of social distancing apply here. The Financial Express. Available from https://www. financialexpress.com/industry/technology/lockdown-effect-norules-of-social-distancing-apply-here/1946444/

Social Care Institute for Excellence. (2020). Domestic violence and abuse: Safeguarding during the COVID-19 crisis, 2020. Available from: https://www.scie.org.uk/care-providers/coronavirus-covid19/safeguarding/domestic-violence-abuse

Stark, E. (2012). Looking beyond domestic violence: Policing coercive control. Journal of Police Crisis Negotiations, 12(2), 199-217. https://doi.org/10.1080/15332586.2012.725016.

Taylor-Dunn, H., Bowen, E., \& Gilchrist, E. A. (2018). Reporting harassment and stalking to the police: A qualitative study of victims' experiences. Journal of Interpersonal Violence. https://doi.org/10. $1177 / 0886260518811423$.

UNDP. (2020). Brief: Gender-based violence and COVID-19. New York: United Nations Development Programme.

Wang, C., Pan, R., Wan, X., Tan, Y., Xu, L., Ho, C. S., \& Ho, R. C. (2020). Immediate psychological responses and associated factors during the initial stage of the 2019 coronavirus disease (COVID-19) epidemic among the general population in China. International Journal of Environmental Research and Public Health, 17(5), 1729. https://doi.org/10.3390/ijerph17051729.

Weller, M., Hope, L., \& Sheridan, L. (2013). Police and public perceptions of stalking: The role of prior victim-offender relationship. Journal of Interpersonal Violence, 28(2), 320-339.

Williamson, E., Lombard, N., \& Brooks-Hay, O. (2020). Domestic violence and abuse, coronavirus, and the media narrative. Journal of Gender-Based Violence., 11, 261-262. https://doi.org/10.1332/ $239868020 X 15893043718030$.

Woodlock, D. (2017). The abuse of technology in domestic violence and stalking. Violence Against Women, 23(5), 584-602. https://doi.org/ $10.1177 / 1077801216646277$.

Publisher's Note Springer Nature remains neutral with regard to jurisdictional claims in published maps and institutional affiliations. 